\title{
BMJ Open Scoping review of mental health in prisons through the COVID-19 pandemic
}

\author{
Luke Johnson (D) , ${ }^{1}$ Kerry Gutridge, ${ }^{2}$ Julie Parkes, ${ }^{1}$ Anjana Roy, ${ }^{3}$ Emma Plugge ${ }^{1,3}$
}

To cite: Johnson L, Gutridge K, Parkes J, et al. Scoping review of mental health in prisons through the COVID-19 pandemic. BMJ Open 2021;11:e046547. doi:10.1136/ bmjopen-2020-046547

- Prepublication history and additional supplemental material for this paper are available online. To view these files, please visit the journal online (http://dx.doi.org/10.1136/ bmjopen-2020-046547)

LJ and $K G$ are joint first authors.

Received 03 November 2020 Revised 13 April 2021 Accepted 03 May 2021

\section{Check for updates}

(c) Author(s) (or their employer(s)) 2021. Re-use permitted under CC BY-NC. No commercial re-use. See rights and permissions. Published by BMJ.

${ }^{1}$ Department of Primary Care, Population Sciences and Medical Education, University of Southampton Faculty of Medicine, Southampton, UK ${ }^{2}$ Centre for Women's Mental Health, Division of Psychology and Mental Health, School of Health Sciences, The University of Manchester Faculty of Biology Medicine and Health, Manchester, UK

${ }^{3}$ Health and Justice Team, Alcohol, Drugs, Tobacco and Justice Division, Public Health England, London, UK

Correspondence to

Dr Luke Johnson;

I.johnson@soton.ac.uk

\section{ABSTRACT}

Objective To examine the extent, nature and quality of literature on the impact of the COVID-19 pandemic on the mental health of imprisoned people and prison staff.

Design Scoping review.

Data sources PubMed, Embase, CINAHL, Global Health, Cochrane, PsycINFO, PsychExtra, Web of Science and Scopus were searched for any paper from 2019 onwards that focused on the mental health impact of COVID-19 on imprisoned people and prison staff. A grey literature search focused on international and government sources and professional bodies representing healthcare, public health and prison staff was also performed. We also performed hand searching of the reference lists of included studies.

Eligibility criteria for selection of studies All papers, regardless of study design, were included if they examined the mental health of imprisoned people or prison staff specifically during the COVID-19 pandemic. Imprisoned people could be of any age and from any countries. All languages were included. Two independent reviewers quality assessed appropriate papers.

Results 0 f 647 articles found, 83 were eligible for inclusion, the majority (58\%) of which were opinion pieces. The articles focused on the challenges to prisoner mental health. Fear of COVID-19, the impact of isolation, discontinuation of prison visits and reduced mental health services were all likely to have an adverse effect on the mental well-being of imprisoned people. The limited research and poor quality of articles included mean that the findings are not conclusive. However, they suggest a significant adverse impact on the mental health and wellbeing of those who live and work in prisons.

Conclusions It is key to address the mental health impacts of the pandemic on people who live and work in prisons. These findings are discussed in terms of implications for getting the balance between infection control imperatives and the fundamental human rights of prison populations.

\section{INTRODUCTION}

In March 2020, the WHO declared a COVID-19 pandemic. ${ }^{1}$ As of 31 March 2021, there have been more than 127 million confirmed infections worldwide with SARS-CoV-2, resulting in more than 2.5 million deaths. ${ }^{2}$

There are over 11 million people imprisoned globally. ${ }^{3}$ This population is particularly susceptible to COVID-19 because of

\section{Strengths and limitations of this study}

- The first scoping review of mental health in prisons during the COVID-19 pandemic.

- We report our rigorous methodology in the format of the Preferred Reporting Items for Systematic Reviews and Meta-Analyses extension for Scoping Reviews to improve our review's transparency, accuracy and completeness.

- Our search strategy and inclusion criteria were broad, identifying comprehensively the relevant literature with clear implications for research and policy.

- The review identified key challenges to mental health in prisons during the pandemic for further research.

- The primary limitation of the study is the limited and low-quality research available within this review, which therefore means it is difficult to draw firm conclusions from the findings.

overcrowded, poorly ventilated and often insanitary environments and suboptimal healthcare services. Frequent staff changeover and movement of imprisoned people in and out of and between prisons contribute to multiple entry points for COVID-19 and the potential for rapid spread once introduced. ${ }^{45}$

Imprisoned people are at high risk for severe COVID-19 due to a high burden of chronic diseases, such as diabetes and hypertension. Also, people from black and minority ethnic groups are often over-represented, and such individuals have a poorer prognosis. ${ }^{67}$ It is therefore clear that imprisoned people are at high risk for severe COVID-19, which is likely to result in significant stress and anxiety within this population. ${ }^{8-12}$ This may be exacerbated further by the infection prevention and control measures in prisons, which focus on restricting prisoner access to each other and outside visitors. ${ }^{13-16}$ Measures implemented include social distancing, cancelling all visits and limiting the time that prisoners spend outside their cell. This has resulted in imprisoned people being locked into cells for 
23 hours or more each day. Comparisons could be drawn between this isolation and solitary confinement,${ }^{15}$ which has been shown to impact on mental health. ${ }^{17}{ }^{18}$ Furthermore, imprisoned people already have a high burden of mental health issues and substance use. ${ }^{719} 20$ Prison staff also have a high burden of mental health conditions. ${ }^{21} 22$ They face significant pressure from working in prisons, which is likely to be exacerbated by the pandemic. ${ }^{923}$

We conducted a scoping review of literature related to COVID-19 and mental health in both prison staff and residents. The review aimed to examine the extent, nature and quality of literature on the impact of the COVID-19 pandemic on the mental well-being of imprisoned people and prison staff. We have also summarised and analysed the research findings and highlighted gaps in the evidence base.

\section{METHODOLOGY}

We conducted a scoping review using the methodology described by Arksey and O'Malley. ${ }^{24}$ We adhered to the five stages of the scoping review process: (1) identifying the research question, (2) identifying relevant studies, (3) study selection, (4) charting the data and (5) collating, summarising and analysing the included literature. We have reported this review in accordance with the guidance in the Preferred Reporting Items for Systematic Reviews and Meta-Analyses extension for Scoping Reviews. ${ }^{25}$

\section{Identifying the research question}

Our research question was 'what is the extent, nature and quality of the literature on the impact of the COVID-19 pandemic on the mental health of imprisoned people and prison staff?'. We included substance misuse within the definition of mental health.

We used Ako et $a l \mathrm{~s}^{26}$ definition of 'prison' as representing 'detention facilities housing both on-remand and convicted people. These settings included prisons, police holding cells, pretrial detention, closed youth institutions and camps where drug users are forced into mandatory labour as means of rehabilitation'. We also included immigration detention centres.

\section{Identifying relevant studies}

We conducted a systematic literature search in nine databases (PubMed, Embase, CINAHL, Global Health, Cochrane, PsycINFO, PsychExtra, Web of Science and Scopus) from 2019 onwards, since this is when COVID-19 was identified. The search was carried out on 5 March 2021. These databases reflect the breadth of disciplines within this field. We kept search terms broad to maximise sensitivity (see online supplemental appendix 1). We also searched grey literature, focusing on official channels of information such as international and government sources and professional bodies representing healthcare, public health and prison staff. We hand-searched the reference lists of included studies.

\section{Study selection}

We screened articles by title and abstract for potentially eligible studies and obtained the full text. We included papers that met the eligibility criteria:

- The article must examine the mental health of imprisoned people or prison staff, of any age and from any country in any language.

- The article must look specifically at the mental health effects of the COVID-19 pandemic.

- All study designs will be included.

Papers reporting research data were evaluated for research quality in line with scoping review adaptations suggested by Pham $e t a l{ }^{27}$ We used the relevant National Institutes of Health's quality assessment tools. ${ }^{28}$ Opinion pieces, case studies and grey literature were not quality assessed.

\section{Charting, collating, summarising and analysing the data}

We charted the data; key data were entered into a table with the following headings: author, month and year, title; study design; population described or studied; key findings; and recommendations (see online supplemental appendix 2). After familiarisation with the data, three authors (LJ, KG and EP) inductively identified six key themes from the data: fear of COVID-19, changes in movement and activities, changes in communication, changes in mental and substance health services, decarceration and continuity of care and the mental health of prison staff. ${ }^{29}$ These themes were reviewed and finessed with the other authors.

\section{Patient and public involvement}

Discussions with experts with experience who had lived or worked in prisons highlighted the growing importance of mental well-being in prisons during the pandemic. However, they were not involved in the subsequent conduct of the review.

\section{RESULTS}

Our search returned a total of 1080 articles (see figure 1). After removal of duplicates and initial screening, we reviewed 280 articles in full. After reviewing these articles against our exclusion criteria, 83 papers were included (see online supplemental appendix 2).

The majority of papers were opinion pieces, with the exception of 10 case studies, ${ }^{30-39}$ seven guidelines, ${ }^{13-1640-42}$ six literature reviews, ${ }^{43-48}$ five qualitative studies, ${ }^{49-53}$ three cross-sectional studies, ${ }^{54-56}$ three briefings,${ }^{57-59}$ three case studies ${ }^{373960}$ and one study protocol ${ }^{61}$ All assessed studies were found to be of poor quality (see online supplemental appendix 3). Of papers that were focused on a particular country, the countries included were the USA (27), the UK (8), Italy (5), Australia (5) and Canada (2) and then one from Brazil, China, Switzerland, Germany and Nigeria. One paper focused broadly on Africa and another on South America. 


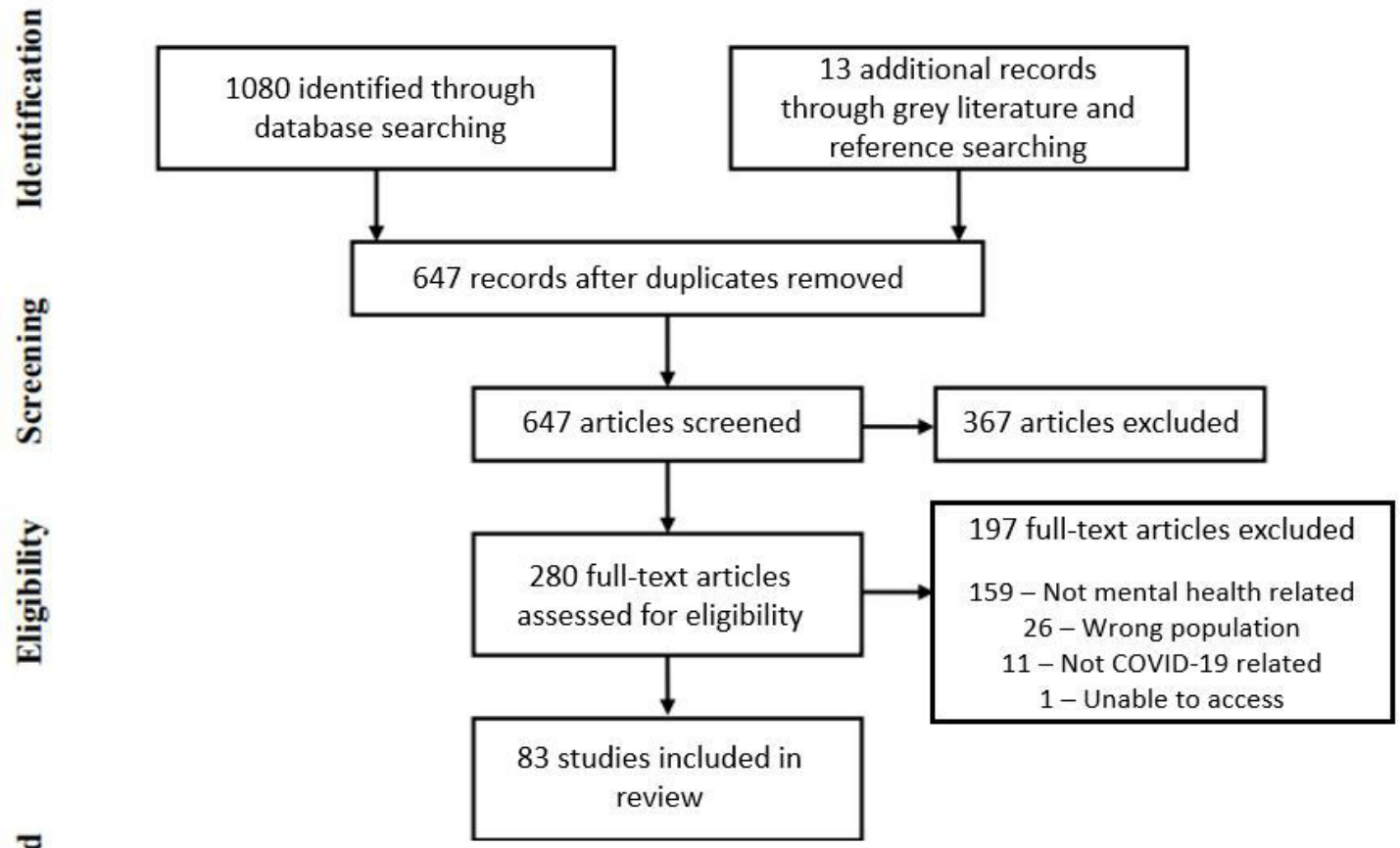

를

Many papers considered prison environments generally, but three examined juvenile correctional facilities (JCFs) in the USA, ${ }^{62-64}$ seven looked at immigration and detention centres ${ }^{844-46606566}$ and one described a mental health support programme for healthcare staff and attorneys working in prisons. ${ }^{37}$

There was little primary data, and that which was identified was conflicting. One study found that recorded incidents of self-harm in $31 \mathrm{UK}$ prisons had decreased by one-third when comparing February with April 2020. ${ }^{67}$ However, three other studies documented higher levels of self-harm across UK prisons. ${ }^{951} 59$

\section{Fear of COVID-19}

The pandemic has induced stress and anxiety in detainees over the risk to themselves and those they love contracting or dying from COVID-19. ${ }^{12} 3964$ 68-71 This is exacerbated by awareness of their health vulnerabilities ${ }^{9}$ and their unhygienic, overcrowded living conditions. ${ }^{8} 1060$ Those left after the pandemic could also experience survivor guilt and grief over loved ones who have died. ${ }^{72}$

\section{Changes in movement and activities}

Movement of many imprisoned people has been severely restricted because of infection control measures. Those with symptoms and positive test results, new to the prison or vulnerable to severe infection are put into isolation, a practice that has negative connotations in prison for its perceived similarity to punitive solitary confinement. $^{35} 434770$ 73-78 Many were concerned that isolation may lead to exacerbations of mental health conditions, anger, depression, psychosis, self-harm and suicide. $^{394656667274-76 \text { 79-84 }}$ There were also concerns that isolation in JCFs will affect young offenders' neurological development. ${ }^{637485}$

In this context, it is important to clarify the difference between isolation and solitary confinement. ${ }^{1573-7581}$ Solitary confinement refers to the confinement of prisoners for 22 hours or more a day without 'meaningful human contact'. ${ }^{86}$ It is used as a disciplinary sanction imposed by prison authorities but is also used as a preventative measure for the protection of the imprisoned person. Imprisoned people in isolation are removed from contact with other members of the prison, usually as an infection prevention and control measure. All prisoners should have resources to make it psychologically bearable-such as a 'television, tablet, radio, reading materials and means of communicating with loved ones, ${ }^{, 73} 85$-as well as access to health professionals and updates on the necessary length for isolation. ${ }^{1373}$ Unless the purpose of their isolation is well defined, prisoners may be reluctant to report symptoms. ${ }^{973}$

Many prisons have significantly restricted prisoner movement regardless of COVID-19 status. $^{63} \begin{array}{lllll}69 & 74 & 75 & 81\end{array}$ Together with social distancing measures, this can mean spending up to 23 hours isolated in an $8 \times 6$ foot cell each day. 59637475 This contrasts with Penal Reform International suggesting blanket isolation measures should be avoided or, if imposed, 'only for the time required to undertake a more individualised and independent medical assessment'. 58

Many activities, including work, education and religious activities, have been stopped ${ }^{59} 6975$ and not substituted by 
recommended socially distant activities. ${ }^{15} 163946$ This is likely to have detrimental effects on mental health. ${ }^{74} 81$ The lack of activities is a consequence of restricting staff numbers on site to minimise infection risk ${ }^{63}$ and the logistical challenge for facilities such as gyms to clean shared equipment. ${ }^{63}$ However, in-cell activities, including exercises, mindfulness, puzzles, videos, colouring and playing cards, offer alternatives. ${ }^{97588}$

Finally, imprisoned people are rarely attending appointments outside of prison, resulting in trials and court hearings being delayed, increased time spent on remand and likely additional distress. ${ }^{39} 75$

\section{Changes in communication}

Many prisons have stopped visits, ${ }^{11} 1239596269747589-92$ which will likely negatively impact mental health. ${ }^{101262697481878991}$ Lack of contact could result in increased anxiety over the health of family members as well as prisoner's own welfare ${ }^{69}$ The European Centre for Disease Prevention and Control calls for special considerations for deciding on visits when infants and children are involved. ${ }^{14}$ However, in the USA, by early April 2020, all JCFs had suspended in-person visits, ${ }^{62}$ and by May 2020, some women in UK prisons had not seen their children in 2 months. ${ }^{59}$

One positive side effect of reduced visits is a reduction in drug availability and drug use in prisons as visits are a drug trafficking route. ${ }^{36767}$ Concurrently, demand for opioid substitution medication has increased, possibly to help with withdrawal symptoms. ${ }^{36} 57$ Managing an increased number of withdrawing people has likely put additional strain on prison staff and healthcare workers.

Ensuring communication with family and friends is maintained is important. One key method by which this has happened is increased telephone access. ${ }^{62} 6367808790$ Additional methods include letter writing, video calls and a prison voicemail service. ${ }^{10} 146263697581878890$ However, these methods are not equally implemented or effective; different prisons have different policies and resources. ${ }^{62} 767784$ For example, secure phone handsets are only available in half of prisons in England and Wales. ${ }^{75}$ Moreover, those with the greatest risk of selfharm and suicide are more likely to be alienated from support networks so least likely to benefit. ${ }^{5967}$

Communication between imprisoned people and staff is also a priority. Levels of education and health literacy are low among imprisoned people, and combined with a tight control of information within prisons, this can lead to the spread of misinformation and fear. ${ }^{80}$ Emphasis must be placed on regular, clear communication to prisoners concerning changes in protocol. ${ }^{31436987}$ The Royal College of General Practitioners emphasises good communication throughout their guidelines for managing COVID-19 in prisons. ${ }^{40}$

\section{Changes in mental and substance health services}

Despite a prevailing belief that the mental health burden will increase, routine services have been deprioritised or withdrawn in many places due to infection risk. ${ }^{9} 545962729394$ This is contrary to the widespread belief that psychiatric and psychological care remains

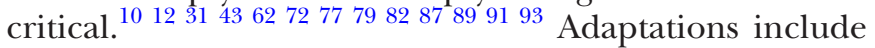
correctional staff providing psychological support, prisoner access to online counselling tools and telepsychiatry. ${ }^{10} 60727995$ Telepsychiatry received particular note, ${ }^{10} 303945546079929697$ with recommendations for US states to waive license requirements to facilitate greater uptake. $^{1098}$

With the reality of rationalised mental health services, articles emphasised the need to optimise triaging to ensure imprisoned people with the highest mental health risk are prioritised; suggested factors include pre-existing mental health condition, risk of harm to self or others, aggression and refusal to eat. ${ }^{972}$ For the in-person mental health appointments that do take place, it is important that staff are risk-assessed and provided with personal protective equipment. ${ }^{41} 72$ A number of articles reported how systems and processes had been modified and developed to ensure that imprisoned people were able to continue with drug treatment. ${ }^{3233} 3642$ In one prison, depot buprenorphine had become first-line treatment for opioid agonist treatment (OAT) ${ }^{36}$

\section{Decarceration and continuity of care}

Many recommended decarceration as a strategy to help reduce infection risk. ${ }^{85} 859399-102$ This has been implemented in several countries including Iran, Turkey, Afghanistan, France, Indonesia and Ethiopia. ${ }^{92} 103104$

However, there are important considerations for the mental health of those released. ${ }^{75} 90105$ First, they will be entering an unfamiliar environment with substantial societal changes, leading to increased stress. ${ }^{68} 75$ Imprisoned people often have a lack of financial and social capital, lower educational attainment and higher rates of unemployment and regularly become homeless, all of which are more challenging with current restrictions. ${ }^{68} 9899105$ Those who return to difficult family situations may be at risk of domestic violence, with restricted options to change living arrangements and challenges to seeking a police protective order if needed. ${ }^{689}$ Second, many community services on which released prisoners often rely have been reduced, altered or discontinued, leading to challenges in accessing care. ${ }^{39} 687590101$ One key area that needs careful planning is OAT. ${ }^{15} 32406199{ }^{105-107}$ In some areas, OAT services are now available via telemedicine, but these require prisoners to be equipped with technology and internet connection prior to release. ${ }^{32} 3361100101$

With these added complications and the rapid speed of decarceration, liaising with community services for follow-up is challenging. ${ }^{16} 687590105$ Close attention must be paid to those released to ensure continuity of healthcare and social care. ${ }^{687599101}$

\section{The mental health of prison staff}

The pandemic has affected the mental health of those who work in prisons. In England and Wales, prison staff absences have doubled. ${ }^{75}$ Staff have been faced with fear 


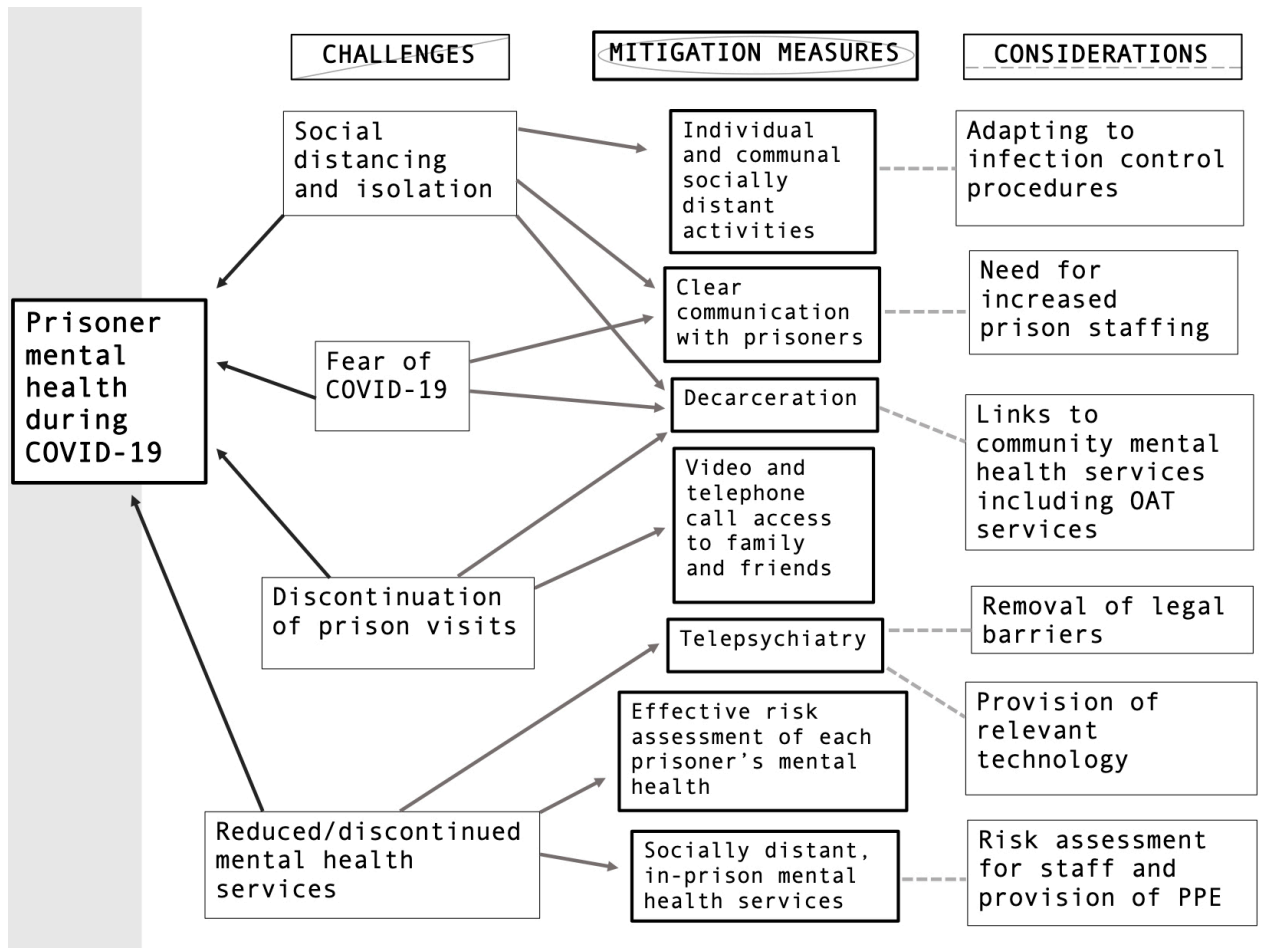

Figure 2 Summary of the challenges and solutions to prisoner mental health during COVID-19. OAT, opioid agonist treatment; PPE, personal protective equipment.

of contracting the virus as well as burnout from operating with reduced numbers. ${ }^{9} 6280$ A diminished workforce will have implications on the mental health of imprisoned people too. ${ }^{975}$ Fewer staff means less opportunity to support imprisoned people and less time to supervise those at high risk of self-harm or suicide. ${ }^{75}$

\section{Summary}

In summary, the reported impacts on the mental health of imprisoned people are overwhelmingly negative, caused not just by fear of COVID-19, but mediated through the regime changes implemented to minimise infection risks. The key challenges can be summed up as social distancing and isolation, discontinuation of prison visits and reduced/discontinued mental health services. These impacts can be ameliorated by measures including the provision of individual and communal socially distant activities, clear communication with prisoners, decarceration, ensuring access to friends and family through telephones and video calls, effective risk assessment of the mental health of imprisoned people, telepsychiatry and socially distant in-person mental health appointments. This is summarised in figure 2.

\section{Discussion}

The review's findings suggest that the pandemic has had a profound effect on the mental health of those living and working in prisons. Isolation is a huge challenge to mental health in prisons. The adverse psychological effects of solitary confinement are well documented 1718108 and include an increased risk of mortality 5 years after release. ${ }^{108}$ Although the reasons for isolation are different, there are likely still negative consequences for mental health. Similarly, visitors have been shown to be positive for the well-being of imprisoned people and linked to reduced recidivism. ${ }^{109}$ Preventing visits is therefore also likely to impact mental health. A rapid review of the psychological impact of quarantine in the wider community showed a detrimental effect on mental health in a wide-ranging and possibly long-lasting way. ${ }^{110}$ Longer quarantine increases the severity of impact, and when a restriction to liberty is imposed rather than voluntary, it leads to more distress and greater long-term mental health complications. ${ }^{110}$

Reduced access to health services is also likely to impact mental health. Since the pandemic started, health services in many countries have developed rapidly, with the widespread adoption of telemedicine. ${ }^{11}$ There are, however, concerns over equity and lack of access to technology in prisons. Even in high-income countries such as the UK, at the start of the pandemic, 50 of 117 prison sites had connectivity too poor to enable video consultation. ${ }^{112}$ With growing recognition that the pandemic is far from over, it is important to address mental health issues now. Prison riots have occurred in Brazil, Colombia, Italy and the USA, ${ }^{10} 1279$ which are linked to the challenges to mental health highlighted in figure $2^{10114379818991113}$ and demonstrate that solutions cannot wait.

The discussion around mental health in prisons throughout COVID-19 is lacking robust evidence. Considering the physical and mental health vulnerabilities of prisoners, ${ }^{671920}$ understanding the impact of COVID-19 and the implemented regime changes is an urgent need. Particularly in the context of mass decarceration, prisons 
are often places of transience, and the unaddressed mental health impact will have downstream consequences on wider society too. Currently, the prison service in England and Wales is evaluating feedback from prison residents and staff to improve management of safety and mental health as the pandemic continues. ${ }^{66} 67$

This review has several key strengths. First, this is the first scoping review of the mental health in prisons during the pandemic. Also, through taking a systematic approach, it has identified comprehensively the relevant literature and gaps in evidence with clear implications for research and policy. However, the poor quality of articles included means that the findings are not conclusive.

More research is urgently needed not only to gain an in-depth understanding of the mental health impact in prisons but also to identify effective interventions. Research also needs to examine the impacts of decarceration. Recently released prisoners are at a high risk of mortality, particularly from drug-related deaths. ${ }^{114}$ Given that drug-related sentences are one of the most common sentences being commuted ${ }^{68104}$ it is important to examine how continuity of care is best maintained on release. The lack of research on prison staff and imprisoned women is notable and should also be addressed.

Prisons should consider the mental well-being of their residents and staff. There needs to be greater provision of in-cell activities and expansion of electronic communications to enable imprisoned people to communicate with health professionals and family and to enable courts to function remotely to prevent the backlog of trials. There must be clear communication with imprisoned people and staff about the public health measures taken so that they know what to expect. These measures, while enabling infection control, must be kept to a minimum to ensure the protection of prisoners' human rights. Healthcare staff have an important role to play in identifying and monitoring the well-being of vulnerable people, maintaining services and responding to health needs. Releasing large numbers of people into the community creates problems for these individuals and requires adequate protections such as appropriate housing and links into health services. All these measures must be underpinned by strong leadership and collaborative working across prison systems, non-governmental organisations and healthcare and social care partners.

\section{CONCLUSION}

The impact of COVID-19 on the mental health of imprisoned people and prison staff is likely to be profound, related not only to fear of COVID-19 but also as a consequence of instituting infection prevention and control measures. Although essential, these must be kept to a minimum and mitigation strategies to maintain mental well-being implemented alongside them. In March 2020, the WHO noted, 'People in prisons and other places of detention are not only likely to be more vulnerable to infection with COVID-19; they are also especially vulnerable to human rights violations'. Given the evidence of impact so far and the reality that this pandemic is far from over, there is an urgent need for action alongside further research to address the adverse mental health consequences of the pandemic on those who live and work in prisons.

Acknowledgements We would like to thank Kelsey Johnson for helping develop the framework image (figure 2) for understanding mental health in imprisoned people throughout COVID-19, and Thiago Bento and Gracia Fellmeth for translations.

Contributors The corresponding author attests that all listed authors meet authorship criteria and that no others meeting the criteria have been omitted. LJ and EP conceived the study. LJ performed the search, and LJ and KG screened articles and assessed their quality. EP acted as coreviewer and quality assessor. All authors contributed substantially to the interpretation of the findings. LJ produced the first draft, and KG, EP, JP and AR revised critically the content. All authors approved the final manuscript. LJ is the overall content guarantor.

Funding The authors have not declared a specific grant for this research from any funding agency in the public, commercial or not-for-profit sectors.

\section{Competing interests None declared.}

Patient consent for publication Not required.

Provenance and peer review Not commissioned; externally peer reviewed.

Data availability statement Data sharing not applicable as no datasets generated and/or analysed for this study. All relevant review information in supplementary material. No primary data analysed.

Supplemental material This content has been supplied by the author(s). It has not been vetted by BMJ Publishing Group Limited (BMJ) and may not have been peer-reviewed. Any opinions or recommendations discussed are solely those of the author(s) and are not endorsed by BMJ. BMJ disclaims all liability and responsibility arising from any reliance placed on the content. Where the content includes any translated material, BMJ does not warrant the accuracy and reliability of the translations (including but not limited to local regulations, clinical guidelines, terminology, drug names and drug dosages), and is not responsible for any error and/or omissions arising from translation and adaptation or otherwise.

Open access This is an open access article distributed in accordance with the Creative Commons Attribution Non Commercial (CC BY-NC 4.0) license, which permits others to distribute, remix, adapt, build upon this work non-commercially, and license their derivative works on different terms, provided the original work is properly cited, appropriate credit is given, any changes made indicated, and the use is non-commercial. See: http://creativecommons.org/licenses/by-nc/4.0/.

\section{ORCID iD}

Luke Johnson http://orcid.org/0000-0002-5585-9512

\section{REFERENCES}

1 World Health Organization. WHO Director-General's opening remarks at the media briefing on COVID-19, 2020. Available: https:// www.who.int/dg/speeches/detail/who-director-general-s-openingremarks-at-the-media-briefing-on-covid-19-11-march-2020 [Accessed 08 Apr 2021].

2 World Health Organization. WHO coronavirus disease (COVID-19) Dashboard, 2020. Available: https://covid19.who.int/ [Accessed 08 Apr 2021].

3 World Prison Brief. World Prison Population List - twelfth edition; 2018.

4 Bick JA. Infection control in jails and prisons. Clin Infect Dis 2007;45:1047-55.

5 Wallace M, Hagan L, Curran KG, et al. COVID-19 in Correctional and Detention Facilities - United States, February-April 2020. MMWR Morb Mortal Wkly Rep 2020;69:587-90.

6 Li J, Huang DQ, Zou B, et al. Epidemiology of COVID-19: a systematic review and meta-analysis of clinical characteristics, risk factors, and outcomes. J Med Virol 2021;93:1449-58.

7 Fazel S, Baillargeon J. The health of prisoners. The Lancet 2011;377:956-65.

8 Garcini LM, Domenech Rodríguez MM, Mercado A, et al. A tale of two crises: the compounded effect of COVID-19 and anti-immigration policy in the United States. Psychol Trauma 2020;12:S230-2. 
9 Kothari R, Forrester A, Greenberg N, et al. COVID-19 and prisons: providing mental health care for people in prison, minimising moral injury and psychological distress in mental health staff. Med Sci Law 2020;60:165-8.

10 Robinson LK, Heyman-Kantor R, Angelotta C. Strategies mitigating the impact of the COVID-19 pandemic on incarcerated populations. Am J Public Health 2020;110:1135-6.

11 Tozzo P, D'Angiolella G, Caenazzo L. Prisoners in a pandemic: we should think about detainees during Covid-19 outbreak. Forensic Sci Int Synerg 2020;2:162-3.

12 Caputo F, Gratteri S, Sacco MA, et al. Covid-19 emergency in prison: current management and forensic perspectives. Med Leg J 2020;88:185-186 https://doi.org/10.1177\%2F0025817220923693

13 Ministry of Justice and Public Health England. Preventing and controlling outbreaks of COVID-19 in prisons and places of detention. UK; 2020.

14 European Centre for Disease Prevention and Control. Infection prevention and control and surveillance for coronavirus disease (COVID-19) in prisons in EU/EEA countries and the UK; 2020.

15 Centers for Disease Control and Prevention. CDC guidance on management of COVID-19 incorrectional and detention facilities; 2020.

16 World Health Organization. Preparedness, prevention and control of COVID-19 in prisons and other places of detention; 2020.

17 Haney C. Prison effects in the era of mass incarceration. Prison J 2012:003288551244860.

18 Arrigo BA, Bullock JL. The psychological effects of solitary confinement on prisoners in supermax units: reviewing what we know and recommending what should change. Int $J$ Offender Ther Comp Criminol 2008;52:622-40.

19 Fazel S, Bains P, Doll H. Substance abuse and dependence in prisoners: a systematic review. Addiction 2006;101:181-91.

20 Fazel S, Danesh J. Serious mental disorder in 23,000 prisoners: a systematic review of 62 surveys. The Lancet 2002;359:545-50.

21 Goldberg P, David S, Landre MF, et al. Work conditions and mental health among prison staff in France. Scand J Work Environ Health 1996;22:45-54.

22 Ferdik FV, Smith HP. Correctional officer. USA: Safety and Wellness Literature Synthesis. National Institute of Justice, 2020.

23 Kinman G, Clements AJ, Hart J. Job demands, resources and mental health in UK prison officers. Occup Med 2017;67:456-60.

24 Arksey H, O'Malley L. Scoping studies: towards a methodological framework. Int J Soc Res Methodol 2005;8:19-32.

25 Tricco AC, Lillie E, Zarin W, et al. PRISMA extension for scoping reviews (PRISMA-ScR): checklist and explanation. Ann Intern Med 2018;169:467-73

26 Ako T, Plugge E, Mhlanga-Gunda R, et al. Ethical guidance for health research in prisons in low- and middle-income countries: a scoping review. Public Health 2020;186:217-27.

27 Pham MT, Rajić A, Greig JD, et al. A scoping review of scoping reviews: advancing the approach and enhancing the consistency. Res Synth Methods 2014;5:371-85.

28 National Institutes of Health. Study quality assessment tools, 2020. Available: https://www.nhlbi.nih.gov/health-topics/study-qualityassessment-tools

29 Braun V, Clarke V. Using thematic analysis in psychology. Qual Res Psychol 2006;3:77-101.

30 Burton PRS, Morris NP, Hirschtritt ME. Mental health services in a U.S. prison during the COVID-19 pandemic. Psychiatr Serv 2021;72:458-60.

31 di Giacomo E, de Girolamo G, Peschi G, et al. Italian prisons during the COVID-19 outbreak. Am J Public Health 2020;110:1646-7.

32 Donelan CJ, Hayes E, Potee RA, et al. COVID-19 and treating incarcerated populations for opioid use disorder. J Subst Abuse Treat 2021;124:108216.

33 Duncan A, Sanders N, Schiff M, et al. Adaptations to jail-based buprenorphine treatment during the COVID-19 pandemic. J Subst Abuse Treat 2021;121:108161.

34 Green AS, Ruchman SG, Katz CL, et al. Piloting forensic telemental health evaluations of asylum seekers. Psychiatry Res 2020;291:113256.

35 Murdoch DJ. British Columbia provincial corrections' response to the COVID-19 pandemic: A case study of correctional policy and practice. Vict Offender 2020;15:1317-36.

36 Roberts J, White B, Attalla D, et al. Rapid upscale of depot buprenorphine (CAM2038) in custodial settings during the early COVID-19 pandemic in New South Wales, Australia. Addiction 2021:116:426-7.

37 Weingarten K, Galván-Durán AR, D'Urso S, et al. The witness to witness program: helping the helpers in the context of the COVID-19 pandemic. Fam Process 2020;59:883-97.
38 Ogunwale A, Majekodunmi OE, Ajayi So, et al. Forensic mental health service implications of COVID-19 infection in Nigeria. Forensic Sci Int 2020;1:100026.

39 Fovet $\mathrm{T}$, Lancelevée $\mathrm{C}$, Eck M, et al. [Mental health care in French correctional facilities during the Covid-19 pandemic]. Encephale 2020;46:S60-5.

40 Royal College of General Practitioners. COVID-19 guidance for healthcare in secure environments. UK; 2020.

41 Royal College of Psychiatrists. COVID-19: secure hospital and criminal justice settings; 2020.

42 Keppler K, Stover H. [Demands for Protection against SARS-CoV-2 in Prisons]. Sucht 2020;66:207-11.

43 Carvalho SGde, Santos ABSD, Santos IM. The pandemic in prison: interventions and overisolation. Cien Saude Colet 2020;25:3493-502.

44 Chaimowitz GA, Upfold C, Géa LP, et al. Stigmatization of psychiatric and justice-involved populations during the COVID-19 pandemic. Prog Neuropsychopharmacol Biol Psychiatry 2021:106:110150.

45 Kois LE, Cox J, Peck AT. Forensic e-mental health: review, research priorities, and policy directions. Psychology, Public Policy, and Law 2021;27:1-16

46 Pedrosa AL, Bitencourt L, Fróes ACF, et al. Emotional, behavioral, and psychological impact of the COVID-19 pandemic. Front Psychol 2020;11:566212.

47 Stephenson T, Leaman J, O'Moore Éamonn, et al. Time out of cell and time in purposeful activity and adverse mental health outcomes amongst people in prison: a literature review. Int $J$ Prison Health 2021:17:54-68.

48 Chevance A, Gourion D, Hoertel N, et al. [Ensuring mental health care during the SARS-CoV-2 epidemic in France: A narrative review]. Encephale 2020;46:S3-13.

49 Gonçalves LC, Baggio S, Weber M, et al. COVID-19 inmate risk appraisal (CIRA): development and validation of a screening tool to assess COVID-19 vulnerability in prisons. Swiss Med Wkly 2021;151:w20471.

50 Maycock M, Dickson G. Analysing the views of people in custody about the management of the COVID-19 pandemic in the Scottish prison estate. Int J Prison Health 2021; ahead-of-print.

51 . CAPPTIVE: Covid-19 Action Prisons Project: Tracking Innovation, Valuing Experience. How prisons are responding to Covid-19 Briefing \#2: Regimes, reactions to the pandemic, and progression. UK Prison Reform Trust; 2021.

52 Testoni I, Francioli G, Biancalani G, et al. Hardships in Italian prisons during the COVID-19 emergency: the experience of healthcare personnel. Front Psychol 2021;12:619687.

53 . CAPPTIVE Covid-19 Action Prisons Project: Tracking Innovation, Valuing Experience. How prisons are responding to Covid-19. Briefing \#3: The prison service's response, precautions, routine health care, disabilities, well-being, mental health, self-harm, and what helped. UK Prison Reform Trust; 2021.

54 Bandara S, Kennedy-Hendricks A, Merritt S, et al. Early effects of COVID-19 on programs providing medications for opioid use disorder in jails and prisons. J Addict Med 2020;14:e257-60.

55 Marmolejo L, Barberi D, Bergman M, et al. Responding to COVID-19 in Latin American prisons: the cases of Argentina, Chile, Colombia, and Mexico. Vict Offender 2020;15:1062-85.

56 Novisky MA, Narvey CS, Semenza DC. Institutional responses to the COVID-19 pandemic in American prisons. Victims \& Offenders 2020;15:1244-61

57 European Monitoring Centre for Drugs and Drug Addiction. Impact of COVID-19 on patterns of drug use and drug-related harms in Europe; 2020.

58 Penal Reform International UK. Coronavirus: healthcare and human rights of people in prison; 2020.

59 HMP Chief Inspector of Prisons. Report on short scrutiny visits to prisons holding women 2020.

60 Green AS, Ruchman SG, Katz CL, et al. Piloting forensic telemental health evaluations of asylum seekers. Psychiatry Res 2020;291:113256.

61 Evans EA, Stopka TJ, Pivovarova E. Massachusetts justice community opioid innovation network (MassJCOIN). J Subst Abuse Treat 2021;108275.

62 Gagnon JC. The solitary confinement of incarcerated American youth during COVID-19. Psychiatry Res 2020;291:113219.

63 León M, Rodas K, Greer M. Leisure behind bars: the realities of COVID-19 for youth connected to the justice system. Leisure Sciences2021;43:218-24.

64 Barnert ES. COVID-19 and youth impacted by juvenile and adult criminal justice systems. Pediatrics 2020;146:e20201299. 
65 Hedrick K, Borschmann R. Addressing self-harm among detained asylum seekers in Australia during the COVID-19 pandemic. Australian and NZ journal of public health 2021;45:80.

66 Wang J, Yang W, Pan L, et al. Prevention and control of COVID-19 in nursing homes, orphanages, and prisons. Environ Pollut 2020;266:115161.

67 Hewson T, Green R, Shepherd A, et al. The effects of COVID-19 on self-harm in UK prisons. BJPsych Bull 2020:1-3.

68 Piel J. Letter to the Editor-Behavioral health implications of inmate release during COVID-19. J Forensic Sci 2020;65:1379-81.

69 Sánchez A, Simas L, Diuana V, et al. COVID-19 in prisons: an impossible challenge for public health? Cad Saude Publica 2020;36:e00083520.

70 Barnert E, Ahalt C, Williams B. Prisons: amplifiers of the COVID-19 pandemic hiding in plain sight. Am J Public Health 2020;110:964-6.

71 Ryan C, Sabourin H, Ali A. Applying an Indigenous and genderbased lens to the exploration of public health and human rights implications of COVID-19 in Canadian correctional facilities. Can J Public Health 2020;111:971-4.

72 Liebrenz M, Bhugra D, Buadze A. Caring for persons in detention suffering with mental illness during the Covid-19 outbreak. Forensic Science International: Mind and Law 2020;1:100013.

73 Cloud DH, Ahalt C, Augustine D, et al. Medical isolation and solitary confinement: balancing health and humanity in US jails and prisons during COVID-19. J Gen Intern Med 2020;35:2738-42.

74 Dutheil F, Bouillon-Minois J-B, Clinchamps M. COVID-19: a prisonbreaker? Can J Public Health 2020;111:480-1.

75 Hewson T, Shepherd A, Hard J, et al. Effects of the COVID-19 pandemic on the mental health of prisoners. Lancet Psychiatry 2020;7:568-70.

76 Brennan PK. Responses taken to mitigate COVID-19 in prisons in England and Wales. Vict Offender 2020;15:1215-33.

77 Heard C. Commentary: assessing the global impact of the COVID-19 pandemic on prison populations. Vict Offender 2020;15:848-61.

78 Lachsz A, Hurley M, Lachsz A. Why practices that could be torture or cruel, inhuman and degrading treatment should never have formed part of the public health response to the COVID-19 pandemic in prisons. Curr Iss Crim Justice.

79 Henry BF, Distancing S. Social distancing and incarceration: policy and management strategies to reduce COVID-19 transmission and promote health equity through Decarceration. Health Educ Behav 2020;47:536-9.

80 Montoya-Barthelemy AG, Lee CD, Cundiff DR, et al. COVID-19 and the correctional environment: the American prison as a focal point for public health. Am J Prev Med 2020;58:888-91.

81 Stewart A, Cossar R, Stoové M. The response to COVID-19 in prisons must consider the broader mental health impacts for people in prison. Aust N Z J Psychiatry 2020;54:1227-8.

82 Goncalves Junior J, JPd S, FCTd S. Analysis of the prison population's mental health in SARS-CoV-2 pandemic: qualitative analysis. Psychiatry Research 2021;296.

83 Mitchell SM, La Rosa NL, Cary J. Considering the impact of COVID-19 on suicide risk among individuals in prison and during reentry. J Crim Psychol.

84 Payne JL, Hanley N. COVID-19 and corrections in Australia: a summary review of the available data and literature. Vict Offender 2020;15:1367-84.

85 Shiple C, Eamranond PP. Letter to the Editor-The disproportionate negative impacts of COVID-19 on the mental health of prisoners. $J$ Forensic Sci 2021;66:413-4.

86 United Nations Office on Drugs and Crime. United nations standard minimum rules for the treatment of prisoners (the Nelson Mandela rules). NY, USA UNODC; 2015.

87 Brelje AB, Pinals DA, Brelje AB. Provision of health care for prisoners during the COVID-19 pandemic: an ethical analysis of challenges and summary of select best practices. Int $J$ of prisoner health

88 SD L, Liu TH, SD L. Correctional System's Response to the Coronavirus Pandemic and Its Implications for Prison Reform in China. Vict Offender 2020;15:959-69.
89 Gulati G, Dunne CP, Kelly BD. Prisons and the COVID-19 pandemic Ir J Psychol Med 2020:1-2.

90 Shepherd S, Spivak BL. Reconsidering the immediate release of prisoners during COVID-19 community restrictions. Med J Aust 2020;213:58-9.

91 Wurcel AG, Dauria E, Zaller N, et al. Spotlight on jails: COVID-19 mitigation policies needed now. Clin Infect Dis 2020;71:891-2.

92 Fovet T, Thibaut F, Thomas P. French forensic mental health system during the COVID-19 pandemic. Forensic Sci Int: Mind and Law 2020;1:100034 https://dx.doi.org/10.1016\%2Fj.fsiml.2020.100034

93 Nweze VN, Anosike UG, Ogunwusi JF, et al. Prison health during the COVID-19 era in Africa. Public Health Pract 2021;2:100083.

94 Zielinski MJ, Hinton KE, Bull CE. COVID-19 highlights the pitfalls of reliance on the carceral system as a response to addiction. J Subst Abuse Treat 2021;122:108190.

95 Oladeru OT, Tran N-T, Al-Rousan T, et al. A call to protect patients, correctional staff and healthcare professionals in jails and prisons during the COVID-19 pandemic. Health Justice 2020;8:17.

96 Gunn J, Taylor PJ, Forrester A, et al. Telemedicine in prisons: a crime in mind perspective. Crim Behav Ment Health 2020;30:65-7.

97 Hewson T, Robinson L, Khalifa N, et al. Remote consultations in prison mental healthcare in England: impacts of COVID-19. BJPsych Open 2021;7:e49.

98 Otugo O, Wages B. COVID-19: the additional sentence for the incarcerated. Health Equity 2020;4:403-5

99 Crowley D, Cullen W, O'Donnell P, et al. Prison and opportunities for the management of COVID-19. BJGP Open 2020;4. doi:10.3399/ bjgpopen20X101106. [Epub ahead of print: 2508 2020].

100 Hawks L, Woolhandler S, McCormick D. COVID-19 in prisons and jails in the United States. JAMA Intern Med 2020;180:1041-2.

101 Sivashanker K, Rossman J, Resnick A, et al. Covid-19 and decarceration. BMJ 2020;369:m1865

102 Canady VA. Bazelon center urges reduction of jail population with MI. Mental Health Weekly 2020;30:7.

103 Pakes F. Coronavirus: why swathes of prisoners are being released in the world's most punitive states, 2020The Conversation. Available: https://theconversation.com/coronavirus-why-swathesof-prisoners-are-being-released-in-the-worlds-most-punitivestates-136563 [Accessed 08 Apr 2021].

104 UNAIDS. COVID-19 in prisons - a ticking time bomb, 2020. Available: https://www.unaids.org/en/resources/presscentre/ featurestories/2020/may/20200513_prisons [Accessed 08 April 2021]

105 Ghosh A. Prisoners with drug use disorders during covid-19 pandemic: caught between a rock and a hard place. Asian $J$ Psychiatr 2020;54:102332.

106 Aslim EG, Mungan MC. Access to substance use disorder treatment during COVID-19: implications from reduced local jail populations. J Subst Abuse Treat 2020;119:108147.

107 Mukherjee TI, El-Bassel N. The perfect storm: COVID-19, mass incarceration and the opioid epidemic. Int J Drug Policy 2020;83:102819.

108 Wildeman C, Andersen LH. Solitary confinement placement and post-release mortality risk among formerly incarcerated individuals: a population-based study. Lancet Public Health 2020;5:e107-13.

109 De Claire K, Dixon L. The effects of prison visits from family members on prisoners' well-being, prison rule breaking, and recidivism: a review of research since 1991. Trauma Violence Abuse 2017;18:185-99.

110 Brooks SK, Webster RK, Smith LE, et al. The psychological impact of quarantine and how to reduce it: rapid review of the evidence. The Lancet 2020;395:912-20.

111 Webster P. Virtual health care in the era of COVID-19. The Lancet 2020;395:1180-1.

112 Edge C, Hayward A, Whitfield A, et al. COVID-19: digita equivalence of health care in English prisons. The Lancet Digital Health 2020;2:e450-2.

113 Pattavina A, Palmieri MJ. Fears of COVID-19 contagion and the Italian prison system response. Vict Offender 2020;15:1124-32.

114 Zlodre J, Fazel S. All-Cause and external mortality in released prisoners: systematic review and meta-analysis. Am J Public Health 2012;102:e67-75 